\title{
Experiências de ensino a distância do gerenciamento ágil de projetos com Scrum e apoio de uma ferramenta para gerência de histórias de usuário
}

\author{
Vinícius Bernardo Silva ${ }^{1}$ \\ Marcelo Werneck Barbosa ${ }^{1}$ \\ Lorena Adrian Cardoso Carvalho ${ }^{1}$
}

\begin{abstract}
Resumo: Observa-se o uso crescente de métodos de gerenciamento ágil de projetos nas organizações. Tais métodos têm características próprias, difíceis de serem totalmente compreendidas pelos alunos somente com base em explicações teóricas. Assim, o ensino de métodos ágeis deve ser feito não só por exposição teórica, mas também com demonstração prática. $\mathrm{O}$ desafio de ensinar tais métodos aumenta em um ambiente de ensino virtual. O objetivo deste trabalho é propor e avaliar uma atividade em grupos a distância para ensino do método ágil Scrum com foco na elaboração e gerência de histórias de usuário, com o apoio da ferramenta Pivotal Tracker. Como contribuição, destaca-se a disponibilização de um tutorial da ferramenta e outros materiais de apoio, que, segundo alunos, contribuiu positivamente para a realização da atividade. O trabalho também promoveu a identificação de questões comuns dos alunos, que podem orientar professores no planejamento de suas aulas e atividades virtuais.
\end{abstract}

Palavras-chave: Ensino de métodos ágeis. Gerenciamento ágil de projetos. Scrum.

\begin{abstract}
It has been observed a growing use of agile project management methods in organizations. Such methods have their own characteristics, which are difficult to comprehend by students based solely on theoretical explanations. Thus, teaching agile methods should be based on hands on activities besides theoretical foundation. The challenge of teaching such methods increases in virtual environments. The objective of this work was to propose and evaluate one group activity in a virtual course with the purpose of teaching the concepts of the Scrum agile method based on user stories with the support of the Pivotal Tracker tool. As contributions of this work, a tutorial of this tool and support materiais for the activity were elaborated and made available for the academic and research community. According to students, the tutorial positively contributed to performing the activity. This work also presents common students questions that can guide teachers on planning their courses.
\end{abstract}

Keywords: Agile project management. Scrum. Teaching agile methods.

\section{Introdução}

O gerenciamento de projetos das áreas de engenharia, administração ou educação tem em comum a necessidade de adoção de uma metodologia que auxilie no planejamento e acompanhamento das atividades necessárias para atingir um conjunto de objetivos pré-definidos em certo prazo, com certo custo e qualidade, por meio da mobilização de recursos técnicos e humanos. Contudo, esse conjunto de objetivos não é fechado, ou seja, é passível de alterações. Por isso, faz-se necessária a adoção de uma metodologia que suporte projetos de escopo aberto, como é o caso dos métodos ágeis de gerenciamento de projetos [1].

\footnotetext{
${ }^{1}$ Instituto de Ciências Exatas e Informática, Pontifícia Universidade Católica, Minas, Belo Horizonte (MG) - Brasil \{vinicius.bernardoesga.pucminas.br, mwerneckepucminas.br, lorena.adrian@sga.pucminas.br\}
}

http://dx.doi.org/10.5335/rbca.2015.5614 
Os métodos ágeis, dentre eles o Scrum, utilizam conceitos de rápido desenvolvimento, agregando valor ao cliente. Por se tratar de um método de valores informais, as metodologias ágeis valorizam mais o que é produzido sem se preocupar tanto com registros e documentação. Uma das premissas desses métodos é a de que seja fácil realizar mudanças no sistema, caso o cliente deseje. Entretanto, essa maior flexibilidade em relação às mudanças pode demandar algumas alterações na maneira como os projetos são conduzidos nas organizações $[1,2,3]$.

Métodos ágeis de gerenciamento de projetos são mais utilizados, não somente para projetos de desenvolvimento de software, mas também para projetos de outras áreas. Logo, o ensino de tais métodos tem sido ampliado em disciplinas de gerenciamento de projetos de cursos de graduação e pós-graduação de ciência da computação, sistemas de informação, administração, engenharia, entre outras áreas. Autores [4] afirmam que o aprendizado dessas disciplinas não tem o mesmo efeito se o aluno não tiver uma vivência prática do conteúdo. Dessa forma, cabe ao profissional docente inserir estratégias instrucionais diferenciadas em suas aulas, tornando o ambiente agradável e potencializando o processo de ensino e aprendizagem. Assim, o ensino de temas como métodos ágeis de gerenciamento de projetos deve envolver, não só exposição teórica e fundamentação dos conceitos, mas também demonstração prática, o que gera um desafio para professores dessas disciplinas.

O estudo de técnicas e ferramentas para o ensino de métodos ágeis intensificou-se nos últimos anos. Vários trabalhos descrevem o desenvolvimento e uso de jogos educacionais, ferramentas e atividades lúdicas para esse contexto, como os trabalhos de $[1,4,5,6,7,8]$. Entretanto, todos esses trabalhos trataram apenas do ensino presencial e envolveram também o desenvolvimento de ferramentas próprias para o ensino do gerenciamento ágil de projetos, algumas vezes limitadas a apenas algumas funcionalidades e avaliadas somente em ambientes acadêmicos. Por sua vez, o ensino a distância viabiliza formas de aprendizagem para cada tipo de assunto, para que o aluno desenvolva sua autonomia intelectual no processo de aquisição de conhecimento. No processo de aprendizagem democrático da educação a distância, pode-se dizer que a autonomia requer disciplina, organização, persistência, responsabilidade e automotivação. O ensino a distância possibilita a eficiência de cada aluno, por flexibilizar o horário para o estudo, ter atendimento personalizado e respeitar o período de concentração e interesse individual de estudo [9].

O gerenciamento ágil de projetos pode contar com ferramentas de apoio. Todavia, pelo contexto de uso em que estão inseridas, as ferramentas utilizadas para o gerenciamento de projetos de aprendizagem devem apresentar, além das funcionalidades básicas necessárias para o acompanhamento do progresso dos projetos, recursos que auxiliem no processo de aprendizagem [1]. A adoção de ferramentas práticas para gerenciamento de métodos ágeis visando à simulação de situações reais auxilia o docente no processo pedagógico além de promover a experiência de uso de ferramentas dos alunos, incentivando-os também à tomada de decisões, à comunicação e ao trabalho em equipe [10].

Dado o contexto apresentado, o objetivo deste trabalho é propor e avaliar o ensino a distância do método ágil Scrum, mais particularmente dos conceitos e técnicas envolvendo a elaboração e gerência de histórias de usuário, com o apoio da ferramenta Pivotal Tracker. A ferramenta foi escolhida por ser de uso simples e completa o suficiente do ponto de vista das funcionalidades necessárias para o ensino dos conceitos planejados. Foi utilizada como unidade de observação uma disciplina virtual de um curso de pós-graduação, para a qual foi elaborado um tutorial da ferramenta Pivotal Tracker, que pode ser utilizada por professores e alunos de disciplinas que abordem métodos ágeis. Além disso, o trabalho também discute dificuldades, lições aprendidas e aspectos específicos do ensino dos métodos ágeis em ambientes virtuais.

Este trabalho está organizado da seguinte forma: na seção 2, descreve-se o referencial teórico sobre os métodos ágeis, particularmente o Scrum, com uma breve descrição das ferramentas de gerenciamento de projetos ágeis pesquisadas e da ferramenta escolhida e utilizada para estudo, o Pivotal Tracker. Na seção 3, tem-se a descrição da metodologia utilizada para coleta de dados, execução e análise dos resultados da pesquisa. Na seção 4, encontra-se o desenvolvimento com as etapas de implementação, os dados coletados, os resultados alcançados e uma avaliação crítica, que compara os resultados esperados com os resultados obtidos. Por fim, a seção 5 trata das conclusões e dos trabalhos futuros. 


\section{Referencial teórico}

Nesta seção, apresenta-se o referencial teórico deste trabalho, que inclui os métodos ágeis, o Scrum e as ferramentas de apoio ao gerenciamento ágil de projetos. Como este relato insere-se em um contexto de ensino a distância, também são apresentadas características dessa modalidade de ensino. São ainda apresentados trabalhos relacionados a este estudo, com foco no trabalho que deu origem à elaboração da proposta usada neste relato.

\subsection{Métodos ágeis e Scrum}

As diretrizes que os métodos ágeis seguem são baseadas em um documento, chamado Manifesto ágil ${ }^{2}$, publicado em 2001. Tal manifesto é composto por um conjunto de quatro valores, que são: indivíduos e interação são mais importantes do que processos e ferramentas; software (ou produto) funcionando é mais importante do que uma documentação abrangente; colaboração do cliente é mais importante do que negociações de contrato; responder a mudanças é mais importante do que seguir um plano.

A metodologia ágil não pode ser definida apenas como uma maneira rápida de desenvolvimento de software e produtos [11], pois, muitas vezes, esse conceito de rapidez carrega o sentido de desordem e processo fracamente definido. Ao contrário dessa definição, as metodologias ágeis garantem rapidez na entrega devido a processos bem definidos e capacidade de adaptação e flexibilidade diante das mudanças de ambiente do produto nos processos. Dos modelos ágeis existentes, tratar-se-á neste trabalho do Scrum, que enfatiza a comunicação presencial e frequente dos envolvidos no projeto [13], o que é essencial para a execução deste trabalho.

Scrum é uma abordagem inovadora e um framework ágil para gerenciar e completar projetos complexos. Scrum foi originalmente elaborado para projetos de desenvolvimento de software, mas funciona bem para qualquer escopo de trabalho completo e inovador [13]. As Sprints são iterações sequenciais e formam um ciclo fixo, durante o qual a equipe se compromete a transformar os requisitos selecionados para aquela entrega em um incremento do produto [14]. Trata-se de um período fixo de tempo de duração de até trinta dias no qual um incremento do produto é gerado. A Sprint inicia-se com uma reunião de planejamento e é acompanhada por reuniões diárias de alinhamento (Daily Scrum). Ao final da Sprint, há uma reunião de revisão na qual os produtos são validados e, ainda, uma reunião de retrospectiva para identificar melhorias no processo. Há alguns papéis esperados no Scrum. O Time Scrum é a equipe responsável pelo desenvolvimento dos entregáveis do produto. O Product Owner é responsável por identificar e priorizar as funcionalidades do produto maximizando seu valor. Por sua vez, o Scrum Master garante que o time de desenvolvimento entenda e aplique a teoria, as práticas e as regras do Scrum no desenvolvimento do produto.

Um dos principais artefatos do Scrum é o Product Backlog, uma lista ordenada de tudo que deve ser feito no projeto. É também chamado de lista de pendências. O Product Backlog não é estático, pois sofre alterações na sua ordem de relevância e também com a entrada de novas funcionalidades. No Scrum, é formado por histórias de usuário. História de usuário é um método para levantamento de requisitos que descreve de forma funcional os requisitos para o cliente ou comprador do projeto [15].

Três aspectos devem ser observados durante o processo de levantamento de requisitos. Inicialmente, as histórias são escritas em cartões, normalmente em texto curto e como forma de lembrete de alguma funcionalidade que ainda deve ser discutida. Em seguida, as histórias são discutidas com o Product Owner por meio de um processo de conversação para melhor detalhar a história. Por fim, os critérios de aceitação devem ser identificados para validar a história. Apesar de o cartão conter a identificação das funcionalidades, isso não é o mais importante [15], mas sim a conversação. Por meio das conversas serão tratados todos os detalhes de cada funcionalidade.

\subsection{Ferramentas de gerenciamento ágil de projetos}

Atualmente, já existem algumas ferramentas de apoio ao gerenciamento ágil de projetos. Algumas dessas ferramentas foram desenvolvidas por meio de projetos de pesquisa e validadas em contextos acadêmicos. Tais ferramentas e seus trabalhos serão discutidos na seção Trabalhos relacionados (2.4). Em um contexto organizacional, podem ser usadas algumas ferramentas, que serão descritas brevemente a seguir. As ferramentas

\footnotetext{
${ }^{2}$ Disponível em: 〈http://www.agilemanifesto.org〉.
} 
apresentadas foram escolhidas por apresentarem funcionalidades mais relacionadas à escrita e à manutenção de histórias de usuário, objeto de estudo deste trabalho.

O Trello ${ }^{3}$ é uma ferramenta colaborativa para gerenciamento de projetos com muitos recursos e usa o paradigma Kanban. Um dos pontos principais do Kanban [2] consiste na elaboração do fluxo de execução do projeto, dentro de um conjunto pré-definido de etapas para as tarefas, em um quadro que pode ser facilmente visualizado e acessado pela equipe do projeto. De forma simplificada, essas etapas podem ser: a fazer, fazendo e feito. Em seguida, as tarefas são individualmente definidas em cartões, que são adequadamente dispostos dentro das etapas [16]. Com o Trello é possível emular os quadros que são comuns em técnicas de gerenciamento ágil, como Scrum e Kanban [17].

Target Process ${ }^{4}$ é uma ferramenta que possibilita o planejamento e o acompanhamento de qualquer processo, como Scrum, Kanban ou outro modelo personalizado. Ela permite a criação de painéis e cartões personalizados, a realização de estimativas de horas por tarefa de um determinado cartão e o compartilhamento dos diversos painéis que podem compor o seu projeto. Permite, ainda, mover muitos cartões para qualquer painel, e proporciona também uma gama de relatórios gráficos, que permite o monitoramento das métricas préestabelecidas. Adapta-se a processos de desenvolvimento de acordo com o modelo de gerenciamento de projetos ágeis que forem pertinentes para a organização. Entretanto, seu uso em ambiente acadêmico pode ser considerado limitado, por ter somente versões pagas.

A ferramenta on-line Pivotal Tracker ${ }^{5}$, acesso em: 15 set. 2014 propõe uma única visão do projeto de desenvolvimento ágil em tempo real e compartilhado com a equipe a partir de uma interface gráfica amigável. A ferramenta permite a criação e o gerenciamento de histórias de usuário por meio de diversos painéis que auxiliam na construção e no gerenciamento dos projetos. O painel Icebox contém as histórias que ainda têm de ser priorizadas e estão em fase de construção. Quando estiver descrita, uma história que se encontra nesse painel pode ser priorizada, arrastando-a para o painel atual ou para o painel de Backlog. O painel atual (Current) armazena as histórias que já foram priorizadas e que fazem parte da Sprint atual. O painel Backlog contém as histórias a serem desenvolvidas ao longo de todo o projeto (lista de pendências). A ferramenta ainda conta com um conjunto de relatórios de acompanhamento.

Dentre as ferramentas estudadas, o Pivotal Tracker foi escolhido por permitir e implementar um fluxo de gerenciamento de histórias de usuário aderente ao projeto de atividade deste trabalho [1]. Além disso, foi obtida uma licença acadêmica para seu uso e estudo na universidade.

\subsection{Ensino a distância}

A educação a distância (EaD) é uma modalidade que busca conciliar o uso das tecnologias ao processo educacional com o intuito de ampliar as possibilidades educacionais. No contexto da EaD, ainda são muitas as questões em análise, como quais são as atribuições do docente, o que se altera no seu fazer e como esse profissional lida com as novas tecnologias educativas, qual o impacto das interfaces informatizadas no processo ensino-aprendizagem, do ponto de vista cognitivo, quais as estratégias elaboradas pelos alunos para navegar nas interfaces informatizadas, e, ainda, como a análise da atividade pode contribuir para melhorar as condições de trabalho dos professores e a qualidade das ferramentas disponibilizadas [11]

No ensino presencial, o convívio entre as pessoas e a troca de experiências por meio de diálogo auxiliam no processo de ensino e podem fornecer a bagagem necessária para os desafios que serão enfrentados após a conclusão do curso. Contudo, paralelo a isso, no ensino a distância, o aluno tem a possibilidade de regrar o seu estudo e conciliá-lo com sua condição de trabalho ou financeira, não tendo a necessidade de contato direto com outras pessoas diariamente, como no ensino presencial [10].

Nos últimos anos, os ambientes virtuais de aprendizagem (AVAs) são cada vez mais utilizados no âmbito acadêmico e corporativo como uma opção tecnológica para atender à demanda educacional. Os AVAs consistem-se em mídias que utilizam o ciberespaço para veicular conteúdos e permitir interação entre os atores do processo educativo. Esses ambientes proveem recursos para dispor grande parte dos materiais didáticos nos mais diferentes formatos, podendo ser elaborados na forma escrita, hipertextual, oral ou audiovisual [18].

${ }^{3}$ Disponível em: $<$ https://trello.com/>.

${ }^{4}$ Disponível em: $<$ http://www.targetprocess.com/>.

${ }^{5}$ Disponível em: <http://www.pivotaltracker.com>. 
Assim, o ensino a distância apresenta um contexto de processo de ensino e aprendizagem diferente, facilitado em alguns aspectos, em função do intenso uso de recursos tecnológicos e informacionais, mas também mais difícil, considerando-se as diferenças entre as comunicações de alunos nesses espaços. Apesar de um aumento no número de trabalhos publicados sobre educação a distância, não foram encontrados trabalhos que avaliassem particularmente o ensino de métodos ágeis nesse contexto. A seção seguinte descreve alguns trabalhos sobre ensino presencial de gerenciamento de projetos e também de métodos ágeis.

\subsection{Trabalhos relacionados}

Jogos têm sido utilizados para apoiar o ensino de diversas áreas do conhecimento e, muitas vezes, despertam maior interesse de parte do aluno. Existe uma grande associação entre jogos e aprendizado [19] e, atualmente, muitos trabalhos são elaborados nesse sentido.

Autores [6] apresentam um estudo de caso que aplica uma dinâmica de ensino sobre a importância das habilidades do relacionamento interpessoal no processo de gerenciamento de equipe nos projetos de software. Já outros [1] desenvolveram o eduScrum, uma metodologia desenvolvida em uma ferramenta que implementa uma solução virtual para o Kanban. Por meio de seus experimentos, foi possível comprovar que os princípios da metodologia Scrum são aplicáveis em um ambiente de aprendizagem. Outro grupo [6] propõe o uso de uma ferramenta que auxilia professores e alunos no ensino-aprendizado do Scrum, baseada na exposição a situações e problemas, simulando um contexto real. O modelo proposto possibilita aos alunos discutir sobre cada decisão e estimativa tomada, revisar decisões, identificar reações positivas e negativas de clientes e responder a eventos que ocorrem no decorrer de uma Sprint.

Planager [20] tem por objetivo explorar os conceitos relativos às atividades de gerência de software apoiados no PMBOK. Foi desenvolvido explorando os conceitos por meio de intuição e visualização. Além do aprendizado, a motivação do jogador é adquirir melhor pontuação para estar mais bem posicionado no ranking. Por ser um jogo digital, requer infraestrutura, como um computador, para utilizá-lo.

O Scrumming [7] simula parte das práticas do Scrum. Trata-se de um jogo mais voltado para o entendimento das Sprints, com uso dos relatórios gráficos de Burndown e gerenciamento do Backlog. Em relação ao uso, em um primeiro momento, o jogo foi concebido pensando em ser utilizado por profissionais da indústria ou alunos de graduação. Entende-se que, por apresentar os conceitos de forma genérica, é possível utilizá-lo com foco na gerência de projetos como um todo, e não apenas em projetos de software.

Autores [4] realizaram um experimento aplicando o Agile Ball Point Game em uma amostra de 31 alunos, formando uma grande equipe. $\mathrm{O}$ uso do jogo educativo permitiu aos alunos vivenciar na prática os conceitos previamente teorizados em sala de aula. Em uma análise inicial dos resultados do experimento, obtidos por intermédio de um questionário, fatores como necessidade de replanejamento, reorganização, comunicação, readaptação e capacidade de liderança foram os itens identificados como essenciais para alcançar os objetivos do jogo.

Vale destacar a pesquisa [1] que serviu como ponto de partida para a elaboração deste trabalho. O objetivo aqui é apresentar uma proposta de atividade com características lúdicas sem a necessidade de usar recursos computacionais para o ensino de histórias de usuário. A atividade é toda baseada no uso de recursos facilmente disponíveis a qualquer professor. O lúdico nessa proposta não está no sentido próprio de brincadeira, mas na proposta de uma atividade que seja dinâmica, interativa e que promova a interação entre membros de um mesmo grupo e ainda entre grupos de alunos. Este trabalho adaptou as atividades lúdicas propostas em [5] para serem realizadas com o apoio da ferramenta de gerenciamento de projetos ágeis Pivotal Tracker e as avaliou em um contexto de ensino a distância.

\section{Procedimentos metodológicos}

Esta pesquisa, em relação à abordagem metodológica, caracteriza-se como qualitativa. Quanto aos objetivos, pode ser caracterizada como exploratória e descritiva, visto que a pesquisa exploratória procura aprimorar ideias ou descobrir intuições e envolve, em geral, um levantamento bibliográfico. A pesquisa descritiva procura descrever fenômenos ou estabelecer relações entre variáveis [21]. A técnica de investigação adotada foi o survey, com instrumento de coleta de questionário. 
O planejamento da atividade da disciplina e a elaboração de materiais de apoio basearam-se na metodologia de desenho instrucional ADDIE ${ }^{6}$ (Analysis, Design, Development, Implementation, Evaluation) definida e também utilizada no trabalho de [5]. A fase de análise caracteriza o processo de definição do conteúdo a ser ensinado. A fase de desenho contempla o processo de determinação da forma de ensino do conteúdo de acordo com os objetivos educacionais. A fase de desenvolvimento é o processo de autoria e produção dos materiais educacionais. A fase de implementação corresponde ao processo de entrega desses materiais para uso, e, por fim, a fase de avaliação permeia todos os processos e guia as atividades pós-desenvolvimento dos materiais. Na fase de análise, fase inicial da metodologia, definiu-se que o conteúdo a ser ensinado seria o método Scrum, com foco no processo de criação de histórias de usuário, sua organização em backlogs, e a evolução das histórias de usuário ao longo do ciclo de vida do Scrum. Tais atividades foram realizadas com e sem o apoio da ferramenta Pivotal Tracker. A motivação é avaliar o uso dessa ferramenta como apoio ao processo de ensino em um ambiente virtual de aprendizagem.

Com base nessa motivação, na fase de desenho da metodologia ADDIE, foram definidos os objetivos e o planejamento das atividades bem como a confecção de todo o material utilizado no decorrer da atividade. Nessa fase, decidiu-se que o conteúdo da atividade deveria abordar a identificação e o registro das histórias em cartões de história, a realização de conversas com o Product Owner (por meio dos fóruns do ambiente virtual de aprendizagem), a realização das estimativas para as histórias seguindo o método Planning Poker, a definição de um Sprint Backlog com base no entendimento e na priorização das histórias, a identificação de tarefas necessárias para implementação e entrega das histórias priorizadas na primeira Sprint e, por fim, a visualização do ciclo de vida das histórias com uso dos recursos de mudança de estado da ferramenta.

$\mathrm{Na}$ fase de desenvolvimento, foram produzidos todos os materiais de apoio para a execução da atividade, como apresentações, confecção dos cartões de história, contas de acesso à ferramenta, questionário de avaliação, tutorial de utilização da ferramenta, documento de visão do produto a ser desenvolvido, enunciado da atividade. Todos os materiais podem ser fornecidos a professores interessados, sob demanda, e são uma contribuição desta pesquisa.

A fase de implementação compreende as atividades orientadas pelo professor aos alunos de um curso a distância de pós-graduação, cuja ementa propõe trabalhar os conceitos do gerenciamento ágil de software. Os alunos receberam o conteúdo sobre métodos ágeis por meio de videoaulas, slides e textos complementares. Cada disciplina do curso deve propor a realização de atividades objetivas para cada unidade e também uma atividade aberta para toda a disciplina. Essa atividade aberta consiste-se na prática sobre Scrum e histórias de usuário. Foi disponibilizado um fórum específico no ambiente virtual de aprendizagem para discutir aspectos e tirar dúvidas do trabalho, com salas separadas para cada grupo.

A atividade proposta foi conduzida em duas fases. Na primeira fase, foi realizado o roteiro proposto por [5] em versão adaptada, que compreende o ensino da técnica de a elaboração de histórias usando os cartões de história, a definição do backlog da primeira Sprint por meio da priorização das histórias no Product Owner, a identificação de tarefas de tais histórias e a realização de estimativa utilizando o método Planning Poker. A segunda fase da atividade compreendeu a utilização da ferramenta Pivotal Tracker para o registro e gerenciamento dos cartões de histórias de usuário, a organização das Sprints e a evolução das histórias segundo ciclo de vida implementado na ferramenta. Os alunos foram instruídos a transcrever os cartões para a ferramenta com o apoio técnico de um tutorial de utilização e configuração da ferramenta, disponibilizado pelo professor no ambiente virtual da matéria.

A Tabela 1 exibe as etapas do desenvolvimento da atividade, identificando os responsáveis por cada atividade. $\mathrm{O}$ enunciado proposto para o trabalho consistia no desenvolvimento de um sistema de gestão de portfólios de projetos. A turma de 109 alunos foi dividida aleatoriamente em grupos de até seis alunos. Os entregáveis solicitados aos grupos foram: evidências dos cartões de história criados; evidências do detalhamento das tarefas; evidências da realização do Planning Poker, registro das histórias na conta da equipe no sistema Pivotal Tracker.

\footnotetext{
${ }^{6}$ Disponível em: <www.indiana.edu/ idt/shortpapers/documents/IDTf_Bic.pdf>.
} 


\section{Resultados}

A disciplina ficou disponível para os alunos por quatro semanas úteis. O fórum da disciplina para discussão de assuntos ligados a todas as unidades de ensino teve um total de 63.273 visualizações e 5.210 mensagens dos alunos, com distribuição ao longo das semanas de aula, conforme mostra a Tabela 2. O fórum para discussão da atividade aberta teve um total de 11.232 visualizações durante toda a disciplina, e 1.176 mensagens.

Tabela 1: Etapas da atividade

\begin{tabular}{|c|c|}
\hline Etapa & Ações realizadas \\
\hline $\begin{array}{l}\text { Etapa } 1-\text { Setup } \\
\text { (professor/tutor) }\end{array}$ & $\begin{array}{l}\text { Criação das contas de e-mail e de usuário no Pivotal Tracker para cada equipe (professor); } \\
\text { divisão da turma em equipes de até seis alunos e comunicação aos alunos (tutor). }\end{array}$ \\
\hline \multirow[t]{3}{*}{$\begin{array}{lr}\text { Etapa } & 2- \\
\text { Primeira } & \text { parte } \\
\text { (grupos) } & \end{array}$} & $\begin{array}{l}\text { Cada equipe deve ler a visão geral do produto, entender as necessidades do cliente e } \\
\text { identificar as histórias de usuário. O professor atuará como Product Owner, auxiliando na } \\
\text { escrita das histórias e informando sua prioridade para a equipe. A equipe pode e deve } \\
\text { consultar por fórum o Product Owner sempre que necessário. As histórias devem ser escritas } \\
\text { usando os cartões de história fornecidos. }\end{array}$ \\
\hline & $\begin{array}{l}\text { A equipe deve distribuir as histórias no Product Backlog em ordem de prioridade. A equipe } \\
\text { deve identificar as histórias mais prioritárias (mínimo duas) que conseguem ser } \\
\text { implementadas na primeira Sprint, de acordo com o tamanho da Sprint definido pela própria } \\
\text { equipe, formando o Sprint Backlog. Para as histórias priorizadas na primeira Sprint, a equipe } \\
\text { deve detalhar as tarefas a serem realizadas para entregar cada uma das histórias. As tarefas } \\
\text { devem ser escritas no verso do cartão ou em uma planilha Microsoft Excel. }\end{array}$ \\
\hline & $\begin{array}{l}\text { A equipe, usando o método Planning Poker adaptado (as opiniões serão expressas entre os } \\
\text { membros no fórum), deve estimar cada uma das tarefas das histórias priorizadas. A equipe } \\
\text { deve calcular e registrar no cartão de história a estimativa total. }\end{array}$ \\
\hline $\begin{array}{lr}\text { Etapa } & 3- \\
\text { Segunda } & \text { parte } \\
\text { (grupos) }\end{array}$ & $\begin{array}{l}\text { A equipe deve transcrever as histórias criadas primeiramente nos cartões para o sistema } \\
\text { Pivotal Tracker. Para a utilização do sistema, a equipe deve consultar o tutorial. A equipe } \\
\text { deve seguir todo o fluxo, desde a implementação até a entrega e aceite pelo cliente das } \\
\text { histórias priorizadas no primeiro Sprint. }\end{array}$ \\
\hline
\end{tabular}

Tabela 2: Dados de uso do fórum da disciplina pelos estudantes

\begin{tabular}{ccc}
\hline $\begin{array}{c}\text { Data término do } \\
\text { período }\end{array}$ & Número de visitas & Número de mensagens \\
\hline $21 / 03 / 2015$ & 10.451 & 495 \\
$28 / 03 / 2015$ & 13.505 & 763 \\
$04 / 04 / 2015$ & 8.749 & 638 \\
$11 / 04 / 2015$ & 6.229 & 601 \\
$18 / 04 / 2015$ & 13.384 & 1.302 \\
$25 / 04 / 2015$ & 9.253 & 1.339 \\
$02 / 05 / 2015$ & 1.702 & 72 \\
\hline Total & 63.273 & 5.210 \\
\hline
\end{tabular}




\subsection{Avaliação da atividade}

Após a execução e a entrega das atividades propostas no ambiente virtual, foi disponibilizado um link para um formulário web, convidando os alunos a avaliar a atividade realizada com o propósito de obter sugestões de melhorias. Dentre os 109 alunos matriculados, 59 responderam o questionário $(54,13 \%)$.

Para avaliar a atividade, foi utilizada a metodologia de avaliação proposta por [22], considerando os aspectos motivação, experiência de usuário e conhecimento. Esses aspectos contemplaram afirmações avaliadas por uma escala Likert (1 como não concordo totalmente, 2 como não concordo parcialmente, 3 como indiferente, 4 para concordo parcialmente e 5 para concordo totalmente).

A avaliação do perfil dos respondentes procurou identificar se os alunos já conheciam a técnica de histórias de usuário e se tinham vivência prática em projetos ágeis. Foi verificado que três alunos $(5,08 \%)$ disseram ter conhecimento da técnica e não ter experiência prática, enquanto 22 alunos $(37,29 \%)$ disseram ter tanto conhecimento da técnica quanto experiência profissional; 24 alunos $(40,68 \%)$ disseram não ter nem conhecimento da técnica, nem experiência profissional, enquanto dez alunos $(16,95 \%)$ afirmaram não ter conhecimento de histórias de usuário, mas já ter experiência profissional com métodos ágeis.

Foi calculada, para cada afirmação, a mediana das respostas obtidas, a mesma adotada e justificada por [3], que considera a principal tendência das respostas da população. Pelo fato de a turma se dividir em relação ao conhecimento e às experiências, decidiu-se apresentar os resultados separando os alunos em dois grupos: os que já conheciam a técnica, ao menos em teoria, e os que não a conheciam. Foram consideradas as afirmações pertinentes para avaliar o nível motivacional dos alunos e o grau de relevância do uso da ferramenta no ensino.

No que se refere aos aspectos motivacionais, os alunos sentiram-se motivados para a realização da atividade proposta, conforme apresentado na Figura 1. O grau de motivação foi considerado próximo entre os alunos que conheciam e os que não conheciam a técnica, sendo que esse grupo mostrou motivação ligeiramente maior no geral.

Figura 1: Avaliação dos aspectos motivacionais

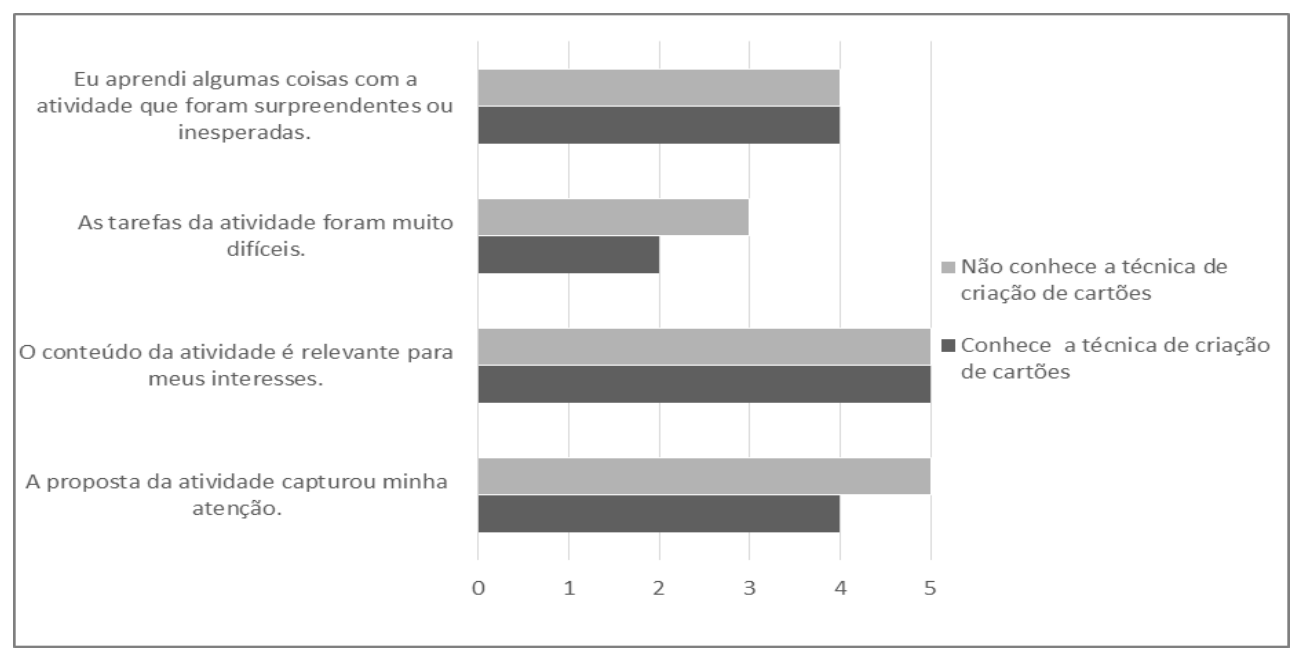

O Scrum defende a unidade da equipe de desenvolvimento. Isso está fortemente relacionado com a presença física da equipe e com interações diárias [23]. Apesar de os dois grupos de alunos (os que já conhecem e os que ainda não conheciam métodos ágeis) considerarem a distância física da equipe como um fator crítico para o desenvolvimento da atividade, de modo geral, pelo resultado das medianas obtidas, pode-se avaliar a utilização da ferramenta como oportuna para o aprendizado dos alunos do curso a distancia. Entende-se que a utilização do fórum de discussão e de uma ferramenta de uso colaborativo, como o Pivotal Tracker, possibilitou romper as barreiras da distância física. 
Figura 2: Avaliação da utilização da ferramenta Pivotal Tracker

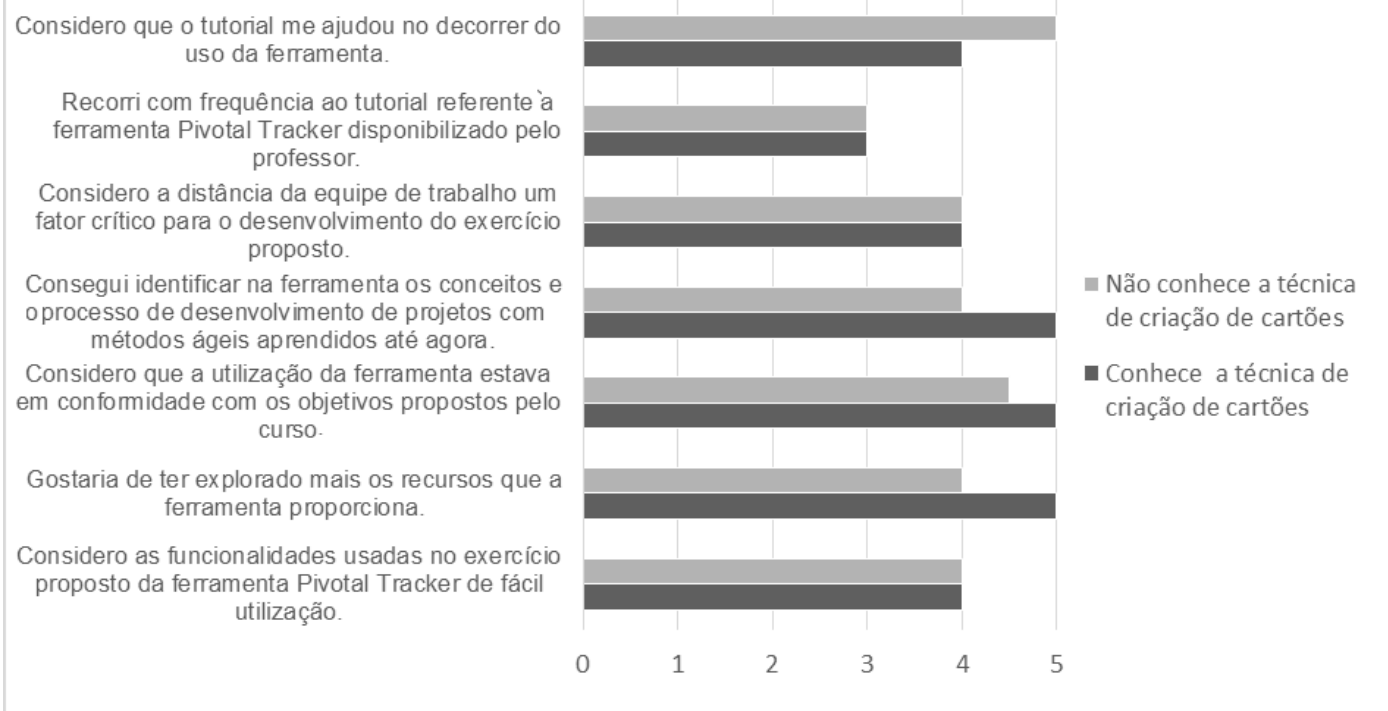

\subsection{Discussões no fórum virtual}

A experiência com a condução do trabalho mostrou que os alunos reagiram positivamente às atividades e empenharam-se em discutir opiniões e dúvidas nos fóruns da disciplina bem como em realizar, de acordo com as exigências do professor, a atividade aberta da disciplina.

A seguir, apresentam-se problemas específicos que os alunos apresentaram na compreensão e aplicação de conceitos e características do gerenciamento de métodos ágeis no trabalho. Essa discussão é realizada por meio de questões apresentadas pelos alunos.

Questão 1 - Como documentar os requisitos não funcionais em projetos ágeis? Trata-se de um desafio comum ao se escrever histórias de usuário [15]. Nesse caso, os alunos foram orientados a tentar seguir o mesmo template para escrita das histórias que tratam de requisitos funcionais, já que muitas vezes é possível também identificar a parte interessada no requisito não funcional. Entretanto, o template foi colocado apenas como um facilitador da escrita. Caso a escrita do requisito não funcional não ficasse clara, eles poderiam utilizar outra forma de escrita que considerassem mais conveniente, mas mantendo a documentação em cartões de história.

Questão 2 - Como diferenciar as histórias nos cartões das tarefas identificadas a partir delas? Do que se trata cada um dos conceitos? Apesar de se considerar que não há nenhuma arte em decompor a história em tarefas [15], uma vez que desenvolvedores de software estariam acostumados a fazer isso, os alunos do curso apresentaram muitas dúvidas em relação a esse aspecto. Os alunos foram orientados a pensar nas tarefas como atividades que devem ser realizadas para se considerar a história implementada. Foram utilizados alguns exemplos [15], como "codificar tela de pesquisa básica", "codificar tela de pesquisa avançada", "escrever código SQL para realizar consultas" e "documentar nova funcionalidade no sistema de ajuda".

Questão 3 - Em que nível de granularidade (detalhamento) as histórias devem ser escritas? Os alunos foram informados que a definição do nível de detalhamento das histórias ficaria a critério de cada grupo. Destacou-se ainda, ao longo das discussões dos requisitos, que eles começariam a entender melhor o sistema e teriam mais capacidade de criar histórias de granularidade menor (com mais detalhes). Percebeu-se que os alunos procuraram definir as histórias em um nível de detalhe a partir do qual a identificação de tarefas poderia ser feita facilmente.

Questão 4 - Como realizar a estimativa com Planning Poker em ambiente virtual uma vez que a técnica assume que os participantes estejam no mesmo local? No enunciado da atividade, foi solicitado aos alunos que encontrassem a melhor forma de realizar as estimativas das tarefas, exigindo-se apenas que houvesse evidência de sua realização. Foram apresentadas como sugestões: o uso do próprio fórum ou de ferramentas de 
comunicação, como o Skype. Alguns grupos utilizaram ferramentas on-line disponíveis gratuitamente para esse fim, como a Planning Poker ${ }^{7}$ e a Planit Poker $^{8}$.

Questão 5 - Quem é o responsável por realizar a priorização das histórias? Mesmo sabendo que o Product Owner é o responsável por essa atividade e que o professor desempenhava esse papel, alguns poucos participantes precisaram confirmar com o professor esse entendimento, e outros chegaram a fazer a priorização, considerando somente as informações disponibilizadas no documento de visão, sem consultar o professor. Esses indivíduos foram alertados de que o Product Owner deveria ser consultado, e as prioridades foram corretamente informadas em seguida.

\section{Conclusões e trabalhos futuros}

O objetivo deste trabalho foi propor e avaliar o ensino a distância do método ágil Scrum, mais particularmente dos conceitos e técnicas envolvendo a elaboração e gerência de histórias de usuário, com o apoio da ferramenta Pivotal Tracker. Essa ferramenta foi escolhida pelo fato de ser de uso simples e completa o suficiente do ponto de vista das funcionalidades necessárias para o ensino dos conceitos planejados. Foi utilizada como unidade de observação uma disciplina virtual de um curso de pós-graduação.

Como contribuição deste trabalho, destaca-se a elaboração de um tutorial da ferramenta Pivotal Tracker, que pode ser utilizado por professores e alunos de disciplinas que abordem métodos ágeis. Além disso, o trabalho também discutiu dificuldades e questões frequentes levantadas pelos alunos durante o ensino dos métodos ágeis no ambiente virtual da disciplina estudada.

A atividade proposta mostrou-se viável para ser realizada em um ambiente virtual. Os participantes mostraram grande interesse na realização do trabalho, e alguns chegaram a propor soluções diferenciadas, como o uso de ferramentas de apoio que não foram indicadas inicialmente pelo professor. Os fóruns da disciplina e o fórum específico para sanar dúvidas da atividade foram intensamente utilizados pelos alunos. As atitudes dos alunos demonstraram trabalho em equipe, rapidez no feedback, auto-organização da equipe, busca por inovação, simplicidade, todos valores admirados e pregados pelo gerenciamento ágil de projetos.

Em relação à utilização do Pivotal Tracker, os alunos afirmaram reconhecer os conceitos dos métodos ágeis implantados no ciclo de vida das histórias de usuário na ferramenta, e até que gostariam de tê-la explorado mais. O reconhecimento da utilidade da ferramenta no aprendizado é mais bem avaliado entre os alunos que já tinham conhecimento prévio das técnicas ágeis, mas também obteve boa avaliação entre os que declararam não ter conhecimento anterior.

Outro resultado relevante é a boa avaliação do tutorial da ferramenta produzido como apoio para realização da atividade da disciplina. Além disso, a utilização dos fóruns de discussão e do Pivotal Tracker possibilitou romper as barreiras da distância. Os materiais de ensino e o tutorial da ferramenta estão disponíveis para uso por outros professores, apenas devem ser solicitados aos autores deste artigo. Como trabalhos futuros, espera-se que outros professores utilizem os materiais elaborados e identifiquem possíveis melhorias. Espera-se, também, evoluir a atividade para ampliar o uso da ferramenta, incorporando mais funcionalidades e conceitos do Scrum.

\section{Referências}

[1] BORGES, K. S.; SCHMITT, A. R.; NAKLE, M. EduScrum: projetos de aprendizagem colaborativa baseados em Scrum. Revista Renote Novas Tecnologias na Educação, Porto Alegre, v. 12, n. 1, 2014.

[2] ANDERSON, D. J. Kanban: successful evolutionary change for you technology business. Sequim: Blue Hole, 2010.

[3] BATISTELlA, P. E.; WANGENHEIM, C. G. V.; CARVALHO; , O. P. Ensinar gerência de equipes em disciplinas de gerência de projetos de software. Revista Brasileira de Informática na Educação, Porto Alegre, RS, v. 21, n. 1, p. 15-22, 2013.

\footnotetext{
${ }^{7}$ http://planningpoker.com

${ }^{8}$ http://www.planitpoker.com
} 
[4] PETRI, G.; MARCON JÚNIOR, R. P. Um jogo educacional para o ensino de metodologias ágeis. In: Fórum de Ensino de Engenharia de Software; Congresso Brasileiro de Software. Anais do V Fórum de Educação em Engenharia de Software. Maceió: Editora da SBC, 2014. p. 66-69.

[5] BARBOSA, M. W.; CARVALHO, L. A.; SILVA, V. B. EUScrum: uma abordagem lúdica para o ensino de estórias de usuário e Scrum. Revista Gestão de Projetos, São Paulo, v. 5, n. 3, p. 44-58, set./dez. 2014.

[6] BARROS, R. M. D.; GESTAL, P. R. E. Proposta de um simulador para auxiliar no processo de ensino do Scrum. In: Simpósio Brasileiro de Sistemas de Informação. Anais do X Simpósio Brasileiro de Sistemas de Informação. Londrina: Editora da SBC, 2014. p.723-736.

[7] ISOTTON, E. N. Scrumming: ferramenta educacional para apoio ao ensino de práticas de SCRUM. Monografia (Trabalho de Conclusão de Curso em Sistemas de Informação) - Faculdade de Informática, Pontifícia Universidade Católica, Porto Alegre, 2008.

[8] JAQUEIRA, A.; COELHO, R.; LUCENA, M. Conduzindo projetos ágeis em um contexto multidisciplinar: um relato de experiência. In: Fórum de Ensino de Engenharia de Software; Congresso Brasileiro de Software, $5^{\text {a }}$ edição. Anais do V Fórum de Ensino de Engenharia de Software... Natal: Editora da SBC, 2012.

[9] FONSECA, R. C. et al. A autonomia intelectual no exercício do aprender a aprender na educação a distância. In: Congresso Brasileiro de Educação Superior à Distância. Anais do XI Congresso Brasileiro de Educação Superior à Distância. Florianópolis: NUTE-UFSC, 2014. p. 1378-1388.

[10] COSTA, V. M. F. et al. Educação a distância x educação presencial: como os alunos percebem as diferentes características. In: CONGRESSO BRASILEIRO DE EDUCAÇÃO SUPERIOR A DISTÂNCIA, 11. Anais... Florianópolis: NUTE-UFSC, 2014. p. 2088-2102.

[11] FLEURY, A. L. et al. Uma experiência de ensino de estatística a distância para um curso de engenharia. Revista de Ensino de Engenharia, Brasília, v. 33, n. 1, p. 37-47, 2014.

[12] OLIVEIRA, E.; LIMA, R. Estado da arte sobre o uso do Scrum em ambientes de desenvolvimento distribuído de software. Revista de Sistema e Computação, Salvador, v. 1, n. 2, p. 106-119, 2011.

[13] WAN, J.; ZHU, Y.; ZENG, M. Case study on critical success factors of running Scrum. Journal of Software Engineering and Applications, v. 6, p. 59-64, 2013. Disponível em $<$ http://www.scirp.org/journal/jsea/>. Acesso em 30 jan. 2016.

[14] PHAM, A.; PHAM, P. Scrum em ação: gerenciamento de desenvolvimento ágil de projetos de software. São Paulo: Novatec, 2012.

[15] COHN, M. User stories applied for agile software development. Boston: Addison Wesley, 2014.

[16] KNIBERG, H.; SKARIN, M. Kanban and Scrum: making the most of both. C4Media. Editora: lulu.com, 2010.

[17] MEIGUINS, A. S. G.; OLIVEIRA, S. R. B. O uso da ferramenta Trello na implementação do modelo MPS para software, nível $G$ de maturidade, em uma empresa de microporte. In: Congresso Brasileiro de Software: Trilha da Indústria. Anais do V Congresso Brasileiro de Software. Porto Alegre: Editora da SBC, 2014. p. 51-54.

[18] MESSA, W. C. Utilização de ambientes virtuais de aprendizagem - AVAS: a busca por uma aprendizagem significativa. Revista Brasileira de Aprendizagem Aberta e a Distância, São Paulo, v. 9, 2010.

[19] PRIKLADNICKI, R.; WANGENHEIM, C. G. O. Uso de jogos educacionais para o ensino de gerência de projetos de software. In: FÓRUM DE ENSINO DE ENGENHARIA DE SOFTWARE; SIMPÓSIO BRASILEIRO DE ENGENHARIA DE SOFTWARE. Anais do I Fórum de Educação em Engenharia de Software. Campinas: Editora da SBC, 2008.

[20] KIELING, E.; PRIKLADNICKI, R. Ensino de gerência de projetos de software com o Planager. In: Simpósio Brasileiro de Informática na Educação. Anais do XVIII Simpósio Brasileiro de Informática na Educação. Porto Alegre, RS: Editora da SBC, 2007. p. 11-20.

[21] DENKER, A. F. M. Pesquisa em turismo: planejamento, métodos e técnicas. São Paulo: Futura, 2007.

Revista Brasileira de Computação Aplicada (ISSN 2176-6649), Passo Fundo, v. 8, n. 1, p. 2-13, abr. 201612 
[22] SAVI, R. Avaliação de Jogos voltados para a disseminação do conhecimento. Tese (Doutorado em Engenharia e Gestão do Conhecimento) - Universidade Federal de Santa Catarina, Florianópolis, 2011.

[23] GOMES, J. E. A. et al. Adoção de metodologias ágeis para produção de jogos sociais com times distribuídos. In: Simpósio Brasileiro de Jogos Digitais. Anais do X Simpósio Brasileiro de Jogos Digitais. Salvador: Editora da SBC, 2011. 